\title{
Un monstruo prodigioso en el Reino de Chile
}

\section{A prodigious monster in the Kingdom of Chile}

\author{
MAURICIO ONETTO PAVEZ \\ Facultad de Ciencias Sociales y Humanidades. Universidad Autónoma de Chile. \\ Correo electrónico: mauricio.onetto@uautonoma.cl
}

Este artículo expone y reflexiona sobre la "monstruosidad" moderna por medio de una exposición y diálogo con una relación impresa, publicada en 1751 en Lisboa, que tradujimos del portugués, cuyo nombre original es: Relação de hum monstruo prodigioso, que appareceu no Reino de Chile entre os montes, que dividem este Reino das dilatadas Provincias de Tucuman, e Paraguay, ou do Rio de Prata, que Sao confinantes com o Brazil. El escrito hace referencia a la aparición de un monstruo en el norte del Reino de Chile durante el siglo XVIII el cual, por su contenido, nos permite reconocer ciertas formas de operación y transmisión de la monstruosidad y de cómo se configuraban los elementos que la componían.

dancia

Palabras claves: Monstruo, Reino de Chile, Modernidad, monstruosidad, ganancia, abun-

This paper seeks to expose and reflect about the modern "monstrosity" through an exposition and dialogue with a printed relation, published in 1751, Lisbon, which we translated from the Portuguese. Its original name is: Relação de hum monstruo prodigioso, que appareceu no Reino de Chile entre os montes, que dividem este Reino das dilatadas Provincias de Tucuman, e Paraguay, ou do Rio de Prata, que Sao confinantes com o Brazil. The writing refers to the sudden appearance of a monster in the north of the Kingdom of Chile during the XVIII century, which, by its content, allows us to recognize certain forms of operation and transmission of monstrosity and how the elements that constituted it were configured.

Key words: Monster, Kingdom of Chile, Modernity, monstrosity, profit, abundance

\footnotetext{
Este artículo es parte de una investigación financiada por Conicyt, Fondecyt de Iniciación No 11150474. Agradecimientos: a la Dra. Andréa Doré, Josefa Correa, Rafael Sagredo y Bastián Nelson por sus comentarios a la traducción de la fuente..
} 
"La América colonial no es una utopía: es una monstruosidad"

(Pastor 1993:106).

Durante 1751 se imprimió en las oficinas de Miguel Manescal da Costa, impresor del Santo oficio, la "Relación de un monstruo prodigioso, que apareció en el Reino de Chile entre los montes que dividen este Reino de las dilatadas Provincias de Tucumán y Paraguay, y del Río de la Plata, que son confinantes con Brasil’. El documento informativo ${ }^{2}$ contó con las "licencias necesarias" del Santo Oficio de Portugal, cuyo Inquisidor General era José de Bragança (Romero 1992: 75). Las razones de por qué se forjó este texto no son expuestas en el escrito ${ }^{3}$. Sin embargo, podemos inferir que con él se buscó reforzar una serie de tópicos e imaginarios políticos, desde lo económico hasta lo religioso (Romero 1992), que provenían de esa zona a Portugal y que, de manera indirecta, afectaban a dicha Monarquía. Esto, debido a que, como se menciona en la misma titulación del documento, se trataba de una zona limítrofe de una de las colonias más importantes de Portugal: el Brasil ${ }^{4}$. En efecto, este pliego aparece justamente en una época en donde había controversias importantes entre la Monarquía de Portugal, La inquisición - guiada desde Lisboa- y el Brasil (Romero 1992). Una de las formas que las autoridades vieron para salir de estos embrollos fue motivar a que surgiera un mayor interés en involucrarse y, por ende, explotar las riquezas de la colonia, puesto que los flujos durante los últimos cincuenta años habían sido importantes, lo que llevó a algunos a denominarla "la edad de oro" (Birmingham 1995: 88-99). Esto lo

\footnotetext{
$1 \quad$ Esta monografía impresa, escrita completamente en portugués, se encuentra en las dependencias del Fondo General Monografías de la Biblioteca Nacional de Portugal, en Lisboa. Su estado de conservación es "legible". Está compuesta por 16 folios escritos con tinta negra, de 21 centímetros de dimensión cada uno, dispuestos en una columna que tiene márgenes moderados. Sólo se observan problemas en el folio 2 de la versión online, debido a que en su parte baja está cortado. El original, al que pudimos tener acceso, no posee este problema, por lo que el lector podrá conocer su contenido desde nuestra traducción. En el texto se exhibe una imagen (monstruo), la cual exponemos en este artículo. Su Signatura Moderna es: H.G. 14991//66 P.

2 Mariela Insúa analiza el carácter informativo que tenían las relaciones de monstruos (2009).

3 La transcripción al espańol de este documento tiene como objetivo presentar a la comunidad académica hispanoparlante una fuente que consideramos de relevancia histórica. Creemos que su lectura permite comprender y avanzar en el conocimiento de las sensibilidades territoriales que se tenían sobre América y Chile en el siglo XVIII, heredadas de los siglos anteriores. El contenido y conexiones que se exhiben en esta fuente, en la cual interactúan territorios, imaginarios y temporalidades de diversa procedencia permiten aseverar esto. El texto que precede la traducción del portugués al español, está enfocado exclusivamente en realizar un análisis historiográfico sobre una de las vetas interpretativas que se pueden hacer de esta "Relación", por sobre un examen, por ejemplo, de tipo literario. Esto se debe a la formación historiográfica del autor. Por tanto, el lector no encontrará precisiones filológicas ni de otra índole vinculadas a la literatura, sino más bien precisiones referidas a los significados y contextos históricos que representa la obra.
}

$4 \quad$ La Inquisición portuguesa contaba con una independencia bastante importante con respecto a Roma. Su poder de acción también estuvo vinculado a tópicos más allá de lo religioso, como lo fue el tema comercial. Véase Bethencourt (1997) y Ebben (1993). 
observamos fundamentalmente en las políticas implantadas por parte del primer ministro Marqués de Pombal. Ahora bien, el interés por lo monstruoso era más común de lo pensado en esos años en Europa (Iglesias 2013) .

Ciertamente, dar a conocer lo que existía en los alrededores del Brasil era una forma de estimular a que las miradas hacia dicha colonia tuvieran más apoyo y generasen mayores ilusiones a los inversionistas, y qué mejor que un monstruo para enaltecer la curiosidad. La escritura buscó, por sobre todo, que se admirase la exuberante naturaleza y las potencialidades de riqueza en dichas tierras, incluso en desmedro de que fuera un territorio de su archirrival (Cf. Doré 2014). El monstruo asoma en las últimas páginas, bajo el formato de una historia que deja un final incierto. Se exhibe su aparición como un prodigio -tanto en su dimensión de maravilla como espanto (Insúa 2009)- en una tierra prodigiosa. Esto nos lleva a concluir que en este tipo de escritos la trayectoria del locus amoenus al locus horridus no es contradictoria sino que complementaria ${ }^{6}$.

Se elige a Chile, probablemente, porque es el territorio que menos se conoce -o del cual se dice no conocerse- o que se (re)presenta como el más lejano, antípoda del Nuevo Mundo y, por tanto, de Portugal. Desde este punto de vista, creemos que se utiliza al Reino de Chile por la doble significación que se había transmitido de él desde la llegada española: una tierra llena de riqueza y fertilidad, pero indomable, tanto por sus habitantes como por ciertos aspectos de su naturaleza que no permitían capturarla totalmente (Cf. Prieto 2010). Considerando esta perspectiva, afirmamos que ha sido la descripción de la abundancia e ilusión de riqueza la que ha predominado y los monstruos han venido a ser casi inexistentes (Godoy 2009)7, de ahí que la fuente que presentamos resulte atractiva de exhibir.

La noción de abundancia se observa desde el primer párrafo de la relación. En este sentido, y considerando la influencia política-religiosa que había detrás del texto, se podría decir que la relación también fue un mapa para entender ciertas dimensiones de lo paradisíaco (Scafi), de un paraíso escondido o de riquezas escondidas.

Ahora bien, el equilibrio y la proyección de futuro dentro del impreso quedó patentada por la fertilidad que se observa en las primeras nueve páginas, de un total de dieciséis del escrito. Se destacan en ellas todos los elementos que componen la naturaleza, como también se habla de los nativos. Con respecto a lo primero, se exhiben y enumeran los diferentes tipos de animales que se encuentran -caballos, jabalíes, aves como los papagayos,

\footnotetext{
5 En cuanto a la aparición de este tipo de formas monstruosas, Vidal (2005) propone que estas -a las que denomina como barrocas o grotescas- son lógicas que aparecen en los momentos de crisis, como respuestas políticas para descongestionar el ambiente social. Su perspectiva nos parece comparable con nuestros argumentos, porque dentro de la fuente hay una dimensión militar como la que él trabaja. En una línea diferente, directamente vinculada a los monstruos, encontramos el trabajo de Cohen (1996).
}

6 Esta circulación entre lo paradisiaco y lo monstruoso lo trabaja para la época Renacentista Morgan (2016).

Por lo general, ha sido la parte de sur de Chile la que más ha estado asociada a sucesos y seres sobrenaturales, y no la parte norte como lo muestra esta fuente. Véase Insúa et al. (2009). 
etc.-, todos con particularidades extraordinarias, pero también las formas geográficas del país que, hasta ese entonces, lo habían hecho distintivo. Sobresale la descripción de la Cordillera como límite geográfico y natural de aquella tierra prodigiosa, terreno donde justamente ocurren los hechos más significativos de la narración.

Del mismo modo, los productos de esta Cordillera nevada se destan como prodigiosos. El agua es uno de los tópicos descrito como tal. Los ríos cristalinos tenían poderes supuestamente curativos, eran capaces de deshacer cualquier indigestión: "pues incluso aunque se haya comido con exceso, bebiendo de esta agua se haya pronto con cocimiento hecho, y con apetito de un nuevo alimento". Ahora bien, este ejercicio retórico no fue algo novedoso en las descripciones sobre lo que ocurría o se podía observar en Chile. Puesto que esta idealización del espacio, que identificamos como una "propaganda territorial", fue una narrativa interna que desde Chile se ejecutó desde el siglo XVI, en parte para contrarrestar la "mala fama" que se había generado entre los españoles sobre este territorio, por las dificultades de conquistarlo. Esto quedó representado tanto de manera oral como de forma escrita en múltiples tipos de escritos: relaciones, cartas, informes, autos, etc. (Onetto 2017).

\section{Monstruosidad en el Reino de Chile}

El monstruo, nombrado como dragón, se enseña como una verdadera novedad dentro de la historia, aunque toma ciertos elementos universales propios de estos seres. La yuxtaposición y superposición de los elementos -injertos- que componen su cuerpo es una de las primeras características (Rojas Mix 2015); también sus colores, sus gritos ensordecedores, su agilidad y las huellas dejadas en su escondite.

Se lo describe como un ser de dos cabezas, una en forma de águila y la otra de león. Desde su frente brotaba una punta parecida a la de los unicornios, en tanto sus extremidades -sus garras- eran las de un león. Su cuerpo es descrito como un acorazado de conchas capaces de resistir al impacto de balas, del cual se desprendían dos grandes bolsillos -como los canguros- en donde la bestia podía portar a sus hijos. En su parte posterior, tenía una gran cola ${ }^{8}$. Lo más significativo para quienes vieron a este monstruo, según el relato, no fue lo extraño de su cuerpo, ni su fuerza - porque mató a muchos de los que intentaron capturarlo-, sino la piedra que llevaba en su frente, reconocida como un Carbúnculo (Rodini 2000). En este sentido, nos parecen sugerentes las palabras de Azucena Hernández-Ramírez, quien indica que "el valor estético de lo monstruoso ofrece también posibilidades de valoración económica y utilitaria" (Hernández-Ramírez, 2016: 70), aunque como indica Izzi, en especial para el caso de los dragones, no se debe dejar de lado el simbolismo que se busca representar con ellos del lugar donde hacen su aparición (Izzi 2000). La imagen que exhibimos a continuación, que corresponde a la portada de la Relación, deja en evidencia la forma en que lo quiso representar el autor(a): \begin{tabular}{l}
\hline El texto deja entrever que el monstruo era hermafrodita. Esto es una constante para describir a los \\
monstruos (Fortanet 2015).
\end{tabular} 


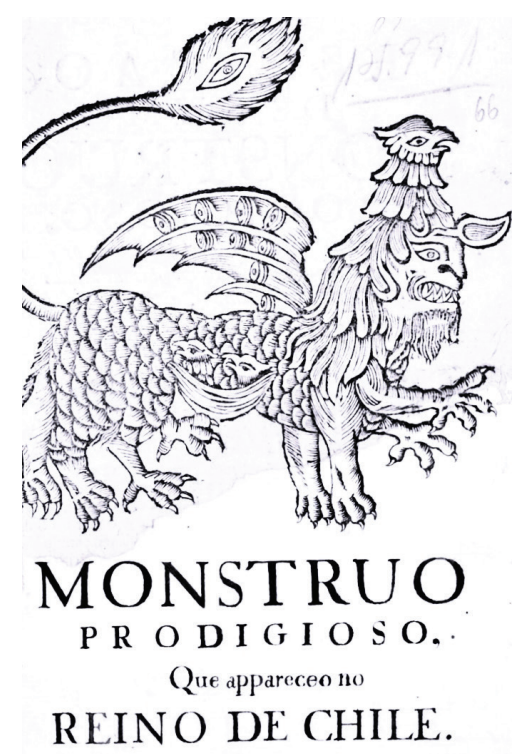

Figura 1

Ahora bien, la monstruosidad que exhibe este impreso es moderna, puesto que desborda la figura del monstruo y atiende más bien a preocupaciones modernas. El monstruo moderno se diferencia del de períodos anteriores en que su existencia se articula en un mismo relato y/o imagen en base a los pilares que conforman y guían a su propia época: conciencia-mundo ${ }^{10}$, circulación, ganancia, inversión y riesgo-catástrofe. Los monstruos que aparecieron en los relatos -relaciones, cartas, informes, etc. ${ }^{11}-\mathrm{o}$ imágenes -grabados, mapas, etc.-, desde el siglo XVI en adelante, se conectaron con cada uno de estos pilares. No fueron únicamente un producto decorativo de lo que se imaginaba o se pensaba que podía existir en un lugar lejano, ni la representación visual de algún peligro en algún territorio o mar ${ }^{12}$. Tampoco se apreciaron como una simple creación de Dios para fines punitivos o

\footnotetext{
$9 \quad$ Algunos artículos que permiten verificar en parte este quiebre son los de Benítez (2015) y López-Ríos (2006).

10 Sobre las dimensiones del concepto consciencia-mundo, véase "Prologue" en Bénat-Tachot et al. (2012).

11 Las Relaciones sobre monstruos fueron numerosas en todo Occidente en esta época (cf. Cereceda 2009; Iglesias 2013). Para el caso americano, ver en especial Miguel Rojas Mix (2015).

12 De acuerdo a Chet Van Duzer (2013), los mapas marítimos de la Edad Media no tenían monstruos, y en el caso de aquellos que sí, dichos monstruos cumplían una labor más bien decorativa, la que tenía un costo mayor. Morgado García (2008) presenta ideas similares.
} 
reparatorios, ni como seres contranaturales ${ }^{13}$, es decir, exclusivamente como la expresión de una extravagancia o de una alteridad marcada ${ }^{14}$. La maravilla o prodigiosidad de estas formas de monstruosidad fue puesta a disposición (geo)políticamente y con un respaldo institucional, asociada ella a alguno de los pilares ya mencionados ${ }^{15}$. Ejemplo de esto se puede ver en el hecho de que la cartografía los haya reproducido constantemente, puesto que era desde ella desde donde comenzaban las empresas de conquista (Izzi 2000).

Desde otra perspectiva, creemos que el monstruo fue la representación del sin control de todas estas conectividades esperadas, de mundos ocultos que no se poseían. Esto insertaría al monstruo moderno en una de las categorías de lo utópico, aunque siempre transhistórico (Cohen 1999: XVI) y político (Oswald 2013: 440 y ss), puesto que su corporalidad - pese a ser amorfa y un collage de diferentes animales o seres míticos ${ }^{16}-$, correspondería a un sin-lugar que estructura un orden fortuito en su doble dimensión, tanto desde el punto de vista de lo inesperado como de lo reditable ${ }^{17}$.

Respecto a las preocupaciones modernas que posee el documento, encontramos, en primer lugar, la abundancia paradisiaca, luego la aparición de lo grotesco y deforme, y finalmente, la asociación general del relato a los pilares mismos de la modernidad: ganancia y empresa $^{18}$. Por otro lado, además del afán de obtener réditos, encontramos la dimensión planetaria del monstruo, tanto en lo comercial como en lo cultural, ya que, en tanto figura, el dragón nos permite verificar la configuración Occidente/Oriente dentro de la propia identificación de este ser. Para Occidente los dragones son parte de las imágenes representativas del Oriente ${ }^{19}$.

\footnotetext{
13 Para adentrarse en la dimensión contranatural de los monstruos, véase Vega (1995).

14 Sobre las limitaciones de la palabra monstruo, véase Izzi (2000) y Oliva (2003).

15 Nos parece importante precisar que nuestra mirada se centra en develar el nexo con la Modernidad y la utilización del monstruo como una forma de aprehenderla. Para profundizar en aspectos referidos al orden y la vida, o la dimensión biopolítica que el monstruo y/o monstruosidad pueden adquirir, ver Torrano (2015).
}

16 Cf. Louis Marin (1973), en el que analiza el caso de La Utopía de Moro. No obstante, el concepto de simulacro de la sintesis se asemeja bastante a lo que proponemos.

$17 \quad$ Sloterdijk presenta una idea de cómo funcionaba esta ilusión: "En sus nuevos y eficientes medios libro popular, libro de viaje, novela, utopía, hoja volante, globo y mapamundi-, la memoria del Nuevo Mundo real y de sus posibles variantes genera un régimen posmetafísico de deseo, que ve su cumplimiento, si no en la proximidad más próxima, sí en una lejanía accesible. Con él se pone en marcha una especie de selffulfilling wishful thinking, que enseña a poner rumbo, fantástica y realmente a la vez, a mundos remotos y a sus riquezas, como si su presencia barruntada en la lejanía fuera ya una promesa de su alcance" (2004: 759).

18 Hernández-Ramírez propone que la monstruosidad para esta época se exhibe bajo la forma de consumo y mercancía: "entre las consecuencias de la abundancia de la materia y la violencia que se ejerce sobre ella, surge el objeto grotesco, deformado y monstruoso, y algo que también apunta a la fuga, al fracaso" (2016: 83). Su demostración la desarrolla a partir la crónica de Oviedo. Otros trabajos que plantean ideas similares sobre la monstruosidad son los de Río Parra (2003) y Barrera (2009). Para una mirada dispar, enfocada en el continente europeo, ver Céard (1977).

19 La construcción orientalista creada por Occidente creemos ha incitado a pensar que los dragones son exclusivos de Oriente (Cf. Said 2005). Desde otra vereda, Reyes Gil habla de que este tipo de monstruos deben 
La monstruosidad moderna también asoma en la forma del riesgo vivido por la expedición que lo descubre. La codicia de explotar una riqueza a cualquier precio poniendo, incluso, en riesgo la propia vida se encuentra latente en el relato. En efecto, la gran cantidad de muertos, descuartizados por el monstruo, demuestra esto. La ubicación de la piedra en la cabeza representa la posesión del futuro esperado por aquellos españoles que arriesgaron su vida por obtenerla sin éxito. Por otro lado, la alteridad, siempre característica cuando se analiza el caso de un monstruo, está desplazada en el horizonte de espera y queda emplazada no en un "otro", sino en sí mismo ${ }^{20}$. Quizás, en este punto del relato se esconde cierto sentido pedagógico, ya que el monstruo funcionó en un escenario espejo que reflejaba la codicia transfigurada de los propios españoles a un lector exterior ${ }^{21}$.

Del mismo modo, la monstruosidad se encuentra presente la exposición de los riesgos que podía tomar cualquier expedición que fuera a "conquistar". Es cierto que en la primera parte del relato se describieron las maravillas de la Cordillera de los Andes, no obstante, de manera posterior, una parte de la descripción se orienta a narrar parte de lo ocurrido a numerosos expedicionarios que intentaron pasar este cordón montañoso durante las épocas de frío. La monstruosidad es reflejo de la pérdida de diferentes partes del cuerpo, en la forma inhumana de perderlas sin dolor, como queda registrado en el texto. El monstruo nace como una representación de estas pérdidas, de la yuxtaposición y superposición de extremidades y corporalidades de diferente procedencia en medio de las alturas. No obstante, este reflejo también es síntesis de una historicidad. El monstruo surge de una lectura vinculada a las ideas acerca de las maravillas de la tierra, pero también como representación de una trayectoria histórica. En este caso, el exceso de frío y "el ejército de estatuas de piedra", como se dice en el texto, fueron parte de un relato histórico creado por la primera expedición que fue a Chile, la del conquistador Diego de Almagro, entre $1535-1536^{22}$.

considerarse como "híbridos transoceánicos", ya que poseen elementos europeos y americanos (2015).

$20 \quad$ Oliva nos presenta dos ideas que se acercan a lo que señalamos: "Hay una relación de similitud entre la desmesura de la geografía americana, los animales fieros e inmensos y las malas costumbres de los hombres", "La idea del monstruo mitad humano, mitad animal, y de ambos sexos, se crea entonces como un fetiche colonial para controlar, al menos imaginariamente, al otro inabordable” (Oliva 2003: 431). Cf. (Reyes Gil 2015).

21 Para Izzi "El monstruo, de portador de un "tesoro" sapiencial, se convierte en el guardián de un tesoro real, y, por consiguiente, en definitiva, en un obstáculo que eliminar. El desdoblamiento de los valores transfiere todos los significados negativos al monstruo, que por consiguiente se encamina irreversiblemente hacia la identificación dragón=diablo, que será sancionada en el Apocalipsis de San Juan” (Izzi 2000: 145).

22 Para Alejandra Vega, se trataría más bien de cuerpos congelados - “objetos inertes que tienen la apariencia de la vida"-, convertidos en piedra, los que proyectaron un carácter maravilloso del frio y ayudaron a dar legibilidad por medio de la cordillera a una cartografía aún desconocida sobre dicho territorio (Vega 2014: 124-125; 133, 196). 


\section{Traducción}

\section{RELACIÓN DE UN MONSTRUO PRODIGIOSO, que apareció en el Reino de Chile entre los montes que dividen este Reino de las dilatadas Provincias de Tucumán y Paraguay, y del Río de la Plata, que son confinantes con Brasil.}

El Reino de Chile es uno de los mejores países que hay en el mundo: está situado al oeste de América Meridional. Limita por la parte norte con el dilatado y riquísimo Reino del Perú. Por el Oriente con las Provincias de Tucumán y Paraguay, por cuyas tierras corre el famoso Río de la Plata que tiene de largo, cuando entra al mar, de sesenta a setenta leguas. Por el sur limita con la Tierra de Magallanes, la cual llega al estrecho del mismo nombre. Por el oeste con el mar Pacífico, cuyo otro nombre es mar del Sur. El clima de este Reino es muy semejante al más temperado de Europa, cuyos frutos, así como el pan, vino, aceite, manzanas, hortalizas, y todo lo que ahí se recolecta es más delicioso y se halla en este Reino con mucho mayor abundancia, por ser la tierra más fértil y favorecida por la gracia del tiempo. Los vinos son tan claros y cristalinos que parecen agua. Sin embargo, son tan fuertes, que los Indios quedan frecuentemente tendidos por tierra y privados de sus sentidos por el efecto de este generoso licor, el cual muchos beben con tanto exceso, al punto de perder su vida, por abrazarles las entrańas con demasiada fuerza. Aquí se ve el Cielo siempre sereno, limpio de nubes y vapores. Y, (Folio 2) cuando algunas veces se cubre o cae alguna lluvia, esta es moderada y en breve tiempo se acaba. Nadie tiene memoria de que en estas tierras hubiesen tempestades y que cayesen rayos o piedras.

La tierra es humedecida por copiosas fuentes de agua cristalina y de grandes cantidades de ríos, con lo que se fertiliza. Las diversas temporadas, de Primavera, Verano, Otońo e Invierno, son muy moderadas. La diferencia con Europa es que cuando es Invierno, aquí es Verano, y en esta proporción se oponen las otras estaciones del ańo. La riqueza de este Reino, tanto el oro como la plata, no es necesario referirla, pues es notoria por la abundancia con que de aquí se ha ido para Espańa. Y sería esta todavía mayor si los Indios no ocultasen las minas más preciosas que hay por las montańas de esta Provincia, con secreto tan inviolable, que tienen por pena de muerte a todos aquellos que las revelasen, de tal suerte que algunos miserables, motivados por una gran amistad, por caricias y por peticiones inoportunas de los Españoles, decidieron revelar alguna, en el mismo camino en que guiaban a los interesados, a pesar de ir acompañados y de ser defendidos por los propios españoles, súbitamente morían antes de que llegaran al sitio en que las dichas minas estaban enterradas, y nadie podía entender cuál era la causa de aquellas muertes tan repentinas.

La abundancia del ganado es increíble, pues es tanta, que además de servir para el sustento cotidiano, todos los ańos se matan muchos millares de vacas, carneros y cabras, solamente para sacarles el cuero, que mandan al Perú, y la carne se echa a los ríos y el mar, para que no se corrompa. Las vacas son tantas que se venden a dieciocho vinténs ${ }^{23}$, los

23 Antigua moneda de cobre utilizada en Portugal y Brasil. 
terneros a siete, los carneros a veinticinco reales, y todavía a menos. No se puede dejar de admirar tanta regalía, porque todo este ganado, después que vino de Espańa para estas provincias, se multiplicó en tan grande número a causa de su abundancia y de las bondades del pasto, que andan en manadas por los campos sin más dueńo que quien lo pueda tomar. La misma suerte tienen otras manadas, como los caballos que andan libremente pastando; y como no cuestan más que el trabajo de cogerlos, se venden muy baratos. Más allá de estos animales, que tuvieron principio en estas tierras con la entrada de los españoles, hay otros naturales de esta Provincia, como son los camellos ${ }^{24}$, que sirven para llevar las cargas, cuya lana es muy preciada, (Folio 3) por ser la más fina. Cuando los jóvenes los inquietan, escupen sobre ellos una saliva de tal cualidad, que donde cae, luego los llena de sarna. Hay otros semejantes a estos que llaman Guanacos, de color rojo, pero muy bravos, los cuales nunca se han domesticado, son tan ligeros que ningún caballo los alcanza en carrera, encontrándose de estos muchas veces cuatrocientos y quinientos. De modo ordinario sólo se caza a los más pequeños, que aún no tienen la fuerza para carreras extensas; la carne es muy sabrosa. En el vientre de este animal se encuentran piedras de Bezoar ${ }^{25}$, que son preciadas. También hay unos animales que llaman Quiriquinchos cuya carne es como la de los lechones. Por los montes hay una especie de puerco que anda en muchas manadas. Cada manada de estas tiene adelante uno como capitán al que van siguiendo los otros. Ninguno se atreve a embestir contra alguna de estas manadas sin matar primero a quien los guía, porque mientras esté vivo, se unen todos y se defienden tan valerosamente que parecen invencibles. Pero si ven muerto a quien los guía, su capitán, huyen todos, y de tal suerte se esparcen que fácilmente se pueden atrapar. El modo como comen también es admirable porque se dividen en dos mitades. Una mitad se arrima a ciertos árboles tiernos y hace caer la flor para que coma la otra, la cual, teniendo comida, va a reemplazar a la que estaba trabajando, y sacude de la misma suerte la flor, para que ella [la otra mitad de los puercos] coma: y de este modo pagan unos a otros los beneficios con mutua correspondencia.

Hay muchas especies de monos y cabras monteses que tienen lana tan suave como la seda. Se ve aquí todo tipo de aves que se crían en Europa y otras especies, siendo el mayor número los Papagayos, que parecen ejércitos que descienden sobre la tierra, o nubes que cubren el cielo, sintiéndose muy de lejos sus gritos, siendo excesivo el estruendo de sus innumerables y desentonadas voces. Hay también un gran número de gallinas ${ }^{26}$, tan grandes como los patos, pero con más grandes alas. Cuando hay matanza acuden a comer la carne que se lanza afuera, y comen tanto que no pueden después volar, y pese a que sus alas son lo bastante grandes para levantar tierra, les hacen mucho peso por la comida, y así fácilmente las matan a golpes en el campo. Cuando no hay matanza, esperan con astucia que los cabritos o corderos se desvíen de los pastores, lanzándose sobre ellos y arrancándoles los ojos (Folio 4)

\footnotetext{
$24 \quad$ Se refiere a las llamas.

25 Tipo de piedra para usos medicinales en la época. 
y comiéndoselos. Otros hacen lo mismo a las gallinas y pollos. Al final son innumerables las especies de aves, que causan gran admiración y entretención de observar, así por su grandeza como por la hermosura de sus plumas y colores. Los nativos de esta Provincia son robustos y valerosos, como tienen mostrada por su resistencia y las repetidas rebeliones que han hecho contra los españoles, causándoles una inexplicable pérdida, cosa que en ninguna otra conquista habían experimentado. Son de estatura alta, pero exceden esta altura aquellos que viven más al sur, los más vecinos a las tierras de Magallanes, cuyos habitantes son de tan deforme altura que parecen Gigantes. A pesar de que los indios de Chile son tan valerosos, carecen de una característica, que en Europa señala el índice de valentía, la cual para ellos es la barba, de la cual están naturalmente desprovistos, y cuando le salen algunos cabellos, lo cual es raro, pronto se los sacan porque es una afrenta tener cabellos en la cara.

Lo que hace más admirable este Reino son las montañas Andes que son las más altas que hay en todo el mundo. Estos comienzan por la parte norte de la Provincia de Quito y continúan sin interrupción alguna hasta la tierra de Magallanes. Tiene de longitud toda esta sierra continuada por mil quinientas leguas, y de ancho cuarenta. Por el medio de estas montańas corre una sierra más alta que llaman Cordillera, la cual comienza con los referidos montes de la Provincia de Quito, y se va elevando más, que en el territorio de Chile es tan alta que sólo para subir requieren, con gran trabajo, los viajeros más de cuatro días. En lo alto de la sierra el aire es tan fino y sutil que no basta para la respiración, por cuya causa es preciso llevar pańos mojados para de este modo volver más espeso y dar más cuerpo al aire para no ahogarse, pues muchos, apenas llegan a este elevado lugar, experimentan grandes ansias, angustias y vómitos, por ser el aire tan delicado que no basta desahogar el corazón, y a todos sucede el respirar más a menudo y más fuerte. Lo que allí les causa mayor admiración es que andan por encima de las nubes, estando éstas muy por abajo, lo que no les permite ver lo que pasa en los valles. Cuando hay lluvia, aparece un arcoiris y los que están encima de dicha sierra lo ven por bajo sus pies y, al mismo tiempo, la tierra está cubierta de espesas nubes (Folio 5) e inundada de una gruesa lluvia, habiendo tempestades, relámpagos y truenos. Principalmente, por la banda de Paraguay, está todo seco en lo alto de la sierra, de ahí se ve el cielo claro, el sol resplandeciente, sin que se pueda tener miedo de las tempestades que ocurren abajo, pues nunca las nubes han llegado a igualar aquellas alturas.

Lo que parece más increíble, y que en verdad se experimenta, son las exhalaciones de fuego que de la tierra vemos tan levantadas, que parecen ir corriendo por el cielo, como unas estrellas, hasta que desaparecen. Allí se ven tan cercanas que, muchas veces, pasan por los pies de las mulas, espantándolas este fuego rápido y tan activo, que les chamusca el pelo y también los vestidos a los caminantes. Al fin, asentados todos los que han subido aquella eminencia, que es más alta que la región media de la esfera del aire que utilizamos, cayendo tanta nieve en aquellas montañas, que las cubre en exceso, que la nieve tiene muchas varas de alto por sobre estas montańas. Sólo en lo más alto de la sierra no cae nieve, ni se encuentran vestigios de que en tiempo alguno allí cayese, señal de que es muy superior a la región del aire donde se forma la nieve. En estas montañas Andes hay dos caminos reales que tienen de ancho treinta pies y de longitud novecientas leguas desde Quito a Chile. Nadie pasa estos caminos de Chile 
por delante porque la mayor parte del año no son penetrables estas montañas, que de allí se continúan hasta el sur, como pronto veremos. En uno de los dos caminos se va por la encima de las montañas, otro por la planicie de los campos junto a las mismas montañas. Ambos caminos son verdaderamente reales y magníficos, en donde los Reyes Incas mostraron su poder, pues teniendo tantas leguas de longitud, estaban todos muy ordenados y embellecidos con piedra labrada y con vertientes curiosas en diversas partes para la recreación de los caminantes. De cuatro en cuatro leguas había palacios soberbios, de gran magnificencia, en que los Reyes Incas se recogían cuando pasaban jornadas en estos caminos. Hoy, todos estos palacios están arruinados y se conservan únicamente algunos como posadas de servicio para pasajeros. Durante el tiempo de invierno dan estas montańas una hermosísima perspectiva, porque como están todas cubiertas de nieve, sin que se vea la tierra, con el reflejo del sol parecen un prodigio, ni hay cosa que agrade más a los ojos que la variedad de resplandores y colores sutilísimos que se observan. Siendo, (Folio 6) sin embargo, la referida nieve tan grata a los que la ven de lejos, es muy nociva a los que la pisan de cerca, pues muchos quedan en ella sepultados, hallándose después de muchos años sus cuerpos enteros y sin corrupción, sin olor, porque el frío de la misma nieve los va secando y los conserva incorruptos como si estuviesen embalsamados. Muchas veces, en verano se han encontrado en aquellas montańas hombres a caballo congelados, como si fuesen de mármol, preservándolos con las mismas acciones que hacían cuando fueron cubiertos por la nieve, y la misma suerte sus cabalgaduras. Por esta causa, ninguno sube a estos montes en invierno. $\mathrm{Y}$ ya ha sucedido a algunos que, caminando desde el Perú hacia Chile al fin del otoño, quedaron atrapados en las montańas a principios del invierno, y fue tan vehemente el frío que padecieron, que a unos se les cayeron los dedos de los pies, a otros de las manos, a muchos las orejas, las narices y otros terminaron ciegos. Y todo esto abruptamente, sin que ellos sintiesen, porque el exceso de frío les quita el dolor y sentimiento. Estas pérdidas lamentadas se experimentan desde hace muchos años, desde que los españoles vinieron a descubrir este Reino, pues quedaron muertos en estas montañas diez mil hombres congelados violentamente por una excesiva frialdad, de suerte que después parecían un ejército de estatuas de piedra.

De este mismo frío procede que los ríos, que nacen de estas mismas montañas, sean tantos que no se sabe su número, siendo en verano muy caudalosos, pero en invierno van casi secos porque el agua se congela con el intenso frío de aquel sitio. Mas, pasada la primavera, corren con tanta agua y tan precipitadamente que si algún caminante se anima a pasarlos, se encuentra sin remedio ante la violencia de algún arrebato de corriente, que no para sino muchas leguas dentro del mar. El agua de todos estos ríos es muy cristalina y fría, y se encuentran en todas ellas características prodigiosas, lo que parece exceder la fe humana, y no sería fácil de persuadir si no hubiera tantos testimonios de vista, verídicos, lo que se observa en dos de estos caudalosos ríos, que es una maravilla de la naturaleza, y viene a ser que pasan los dichos ríos por bajo de dos rocas de piedra, las que están abiertas por la naturaleza, como puentes artificiales, y una de ellas es tan alta que no se oye encima del puente ni el mayor estruendo, que se produce abajo junto al río. Los objetos que allí se encuentran, por grandes que sean, parecen muy pequeños. ¡Tal es la inmensa distancia que va desde aquella roquería 
o puente (Folio 7) natural hasta el fondo por donde corre el río! Hay otros dos ríos también admirables, sumergiéndose por la tierra, van corriendo por debajo de ella, hasta que pasadas muchas leguas reaparecen con una mayor abundancia de agua. El primero es el de Santiago y el segundo el de Poange, el cual pasa por minas de oro, conforme se conjetura por las maravillas que obra, dando salud a muchos achacados y, principalmente, se experimenta su virtud por la eficacia con que deshace toda indigestión, pues incluso aunque se haya comido con exceso, bebiendo de esta agua se haya pronto con cocimiento hecho, y con apetito de un nuevo alimento. Con estas mismas virtudes se encuentran varias fuentes de este Reino. También el célebre río llamado de los Rabudos, porque junto a él habita una nación de Indios que afirman ser personas dignas de crédito, que nacen con colas, como salvajes. No es de menor maravilla el primer río que se encuentra en Chile al entrar desde el Perú, que se llama Salado, porque en realidad es tan salado desde su nacimiento que el agua que se le saca en poco tiempo se convierte en sal, por ello las riberas de este río son tan blancas por la sal que se encuentra congelada, que parecen estar cubiertas de nieve.

Siendo estos montes y toda esta sierra tan abundante de agua, como se ve con los innumerables ríos que allí tienen su origen, no es menos fecunda en actividades de fuego, pues se cuentan dieciséis volcanes o aberturas de la tierra, por donde esta libera fuego, arrojando desde dentro peńascos en brasas que van a caer a gran distancia, llegando a dos leguas alrededor sus cenizas, y escuchándose muchas leguas a lo lejos el formidable estruendo de aquel arrebatado elemento. Se encuentran en esta sierra animales muy feroces como Leones, Tigres, Lobos, Cercopithecus y otros muchos. Aquí se tiene visto el Camaleón que se alimenta sólo con el viento, pero sin hacer mal a ningún ser viviente. También se crían en las mismas montañas unas aves de extraordinaria grandeza que hacen sus nidos debajo de la tierra como los conejos, y los huevos son numerosos y muy sabrosos. Otras fieras que se han visto en esta misma sierra son muy horrorosas, así en grandeza como en aspecto, que dan unos gritos tan tremendos y penetrantes que entrando por los oídos no sólo atemorizan a los que escuchan, sino que hacen daño a la potencia auditiva, dejándolos totalmente sordos.

Supuesto hasta aquí, se han descubierto tantas variedades (Folio 8) de fieras y de salvajes espantosos, pero no hay comparación con un monstruo más horroroso que recientemente se descubrió en estas montañas con mucho temor y admiración de todos los que lo vieron. Sucedió este caso de la siguiente manera:

Caminaba desde el Reino del Perú al Reino de Chile cierto comerciante español llamado Diego Sarmiento de Toledo, acompañado de bastantes servidores y otros pasajeros que se juntaron. Después de muchos días de caminata una noche, teniendo ya armada la tienda para descansar, advirtió que en un valle que estaba próximo a su montańa en donde estaba alojado se veía una luz muy viva, como la de una fogata. Admirado con esta luz repentina llamó a sus compańeros que quedaron sorprendidos con la novedad. Sin embargo, pensaron que serían otros pasajeros que iban desde Chile al Perú, por esto determinaron ir a buscarlos. Subieron la montaña para desde ahí adentrarse en el sitio en donde imaginaron estarían alojados, pero aquí se produjo la mayor sorpresa, porque pese a observar una luz tan clara que alumbraba todo aquel valle, no había ninguna fogata, ni tienda o señal de que 
en todo ese lugar hubiese alguien. Sólo repararon que aquella luz tan clara y resplandeciente salía por entre dos peñascos que había en un costado del valle. Se produjeron varias discusiones, sin saber cómo penetrar, de cuál pudiese ser la causa de tan grande maravilla. Se animaron a bajar y examinar con sus ojos lo que no podrían alcanzar con el discurso. Comenzaron a descender y advirtieron muchas veces algún movimiento de la luz y un estruendo moderado en el lugar. Aquí suspendieron el paso, ya más atemorizados. Más uno sin timidez levantó la voz y con arrogancia preguntó ¿quién estaba en aquel sitio? Apenas se escucharon estas palabras, cuando de repente se oscureció todo el valle, sin divisar alguna señal de aquella luz tan resplandeciente que hasta allí habían visto. Causó esta novedad mayor asombro. Acordaron entre sí qué resolución había de tomarse, porque descender entre tanta oscuridad era peligroso, mucho más no habiendo visto en su vida aquel lugar $\mathrm{y}$, a pesar de estimarse valientes, podían ser allí reducidos en alguna emboscada, sin poder mostrar su valor, si se encontraban en aquel valle alguna compañía numerosa de indios salteadores que estuviesen encubiertos debajo de aquellos peńascos. Retirarse para su alojamiento también era (Folio 9) peligroso, por cuanto podían ser seguidos y, sabiendo donde ellos tenían su alojamiento, se arrojarían de repente sobre ellos, quitándoles no sólo sus mercancías, sino que también su vida. Se dilató [la discusión] largo tiempo hasta que finalmente resolvieron retirarse con el menor ruido que pudiesen.

Así lo ejecutaron, llegando al lugar en que habían armado las tiendas. Apagaron pronto todas las luces para que no dieran señal por dónde ser buscados y acometidos. Para mayor cautela determinaron que estuviese siempre un vigía alternadamente mientras los otros dormían, y que si este sintiese un suceso imprevisto diese señal a los demás para que acudieran. Se detuvieron a descansar, aunque mal podían descansar los que estaban atemorizados y con tantos miedos. Pasada ya la mayor parte de la noche, dio aviso el centinela de que se apreciaba por segunda vez la misma luz que al principio de la noche habían visto, en otro lugar, pero más cerca. Pronto se levantaron todos, salieron de las tiendas, y viendo la luz tan clara que resplandecía en la cima de aquella montaña, se animaron a ir juntos y bien armados a examinar por segunda vez aquel enigma que tanta preocupación les había causado, lo que había que hacer con gran silencio y atención. Subidos a otra altura que permitía descender sobre el lugar donde aparecía la luz, y poniendo atención a la profundidad, no distinguían entre tanta luminosidad a ninguna persona. Sin embargo, notaron que la luz se movía como en la primera ocasión habían observado, y algunas veces se oscurecía, pero pronto volvía a resplandecer como la misma claridad. Bajo estas circunstancias dijo uno de los compañeros que pensaba que aquella luz debía ser la de algún Carbúnculo, del cual muchas veces se ha escuchado contar que era la piedra más preciosa que había en el mundo, que resplandecía de noche y que esta se hallaba en la cabeza de una especie de Dragón que rarísimamente se ha divisado, porque sólo pastan de noche a la luz de aquella brillante piedra que tiene sobre sí mismo. Ante cualquier ruido cubre dicha piedra con una membrana que para eso tiene, dejando todo oscuro, huyendo sin poder ser perseguido, debido a la oscuridad de la noche: $y$ todas estas circunstancias se verifican con aquella luz que al presente veían. 
Oyendo esto todos resolvieron descender hasta el sitio donde se veía salir más intensa la luz, ya fuese por la codicia de la preciosidad (Folio 10) de Carbúnculo, que imaginaban con aquella brillante luz, o por la curiosidad de saber el origen del efecto tan prodigioso. Comenzaron a caminar con bastante recato, silencio, dirigiendo sus pasos hacia unos peńascos debajo de los cuales se veía salir la luz. Cuando iban llegando al final del roquero, para desde allí descubrir alguna cosa, cuando estaban ya muy cerca, uno tropezó con una piedra, y como el camino era tan inclinado cayó precipitadamente despeñadero abajo y, naturalmente, comenzó a gritar que le ayudasen. Con este estruendo se oscureció todo de repente y sintieron un tumulto extraordinario de un animal que iba corriendo por aquellos valles a una velocidad increíble. Se confirmaron todos los presagios, de que sin duda alguna la causa de aquella luz tan brillante que habían visto era un Carbúnculo, y que aquel animal que había huido con tanta destreza era el famoso Dragón, en cuya cabeza se cuenta que crece esta preciosa piedra. Acudieron pronto [a ayudar] al compañero que se había caído, hallándolo bien mal tratado, y lo condujeron a la tienda. Aclarado el día, continuaron su viaje hasta llegar a Copiapó donde dieron noticia al Corregidor que allí reside de lo referido. No hay cosa que más incite los ánimos que la codicia. Se persuadió el Corregidor y todos los demás a quienes se comunicó la noticia de que habían descubierto la mayor preciosidad, con la que serían ricos por toda la vida, y ya no sólo se satisfacerían con un sólo Carbúnculo, mas pensaban en la existencia muchos otros, puesto que discurríase que aquel Dragón no debía ser el único, que en el mismo lugar andarían más de la misma especie, y que para atraparlos sería preciso hacer una montería perfecta, de suerte que no pudiesen escapar aquellas fieras, en cuya desgracia esperaban su mayor felicidad.

Pronto se dio orden para que el domingo siguiente se juntasen todos los soldados, así españoles como indios, para que hicieran un cordón en el lugar observado. Concurrieron todos, viniendo muchos que no estaban obligados, en parte por curiosidad o para ser partícipes de este grande premio que se prometía a quien matase aquellos animales. Llegaron al lugar donde habían pernoctado los pasajeros y de allí se fueron disgregando por aquellos montes de modo que cercaron tres valles profundos. Después de que se distribuyeron, preparados con sus armas, ansiosos de ver aquellos admirables y (Folio 11) preciosos Dragones, soltaron finalmente a los perros que llevaron en gran número y comenzaron a descender por los valles todos los cazadores que tenían en su cuenta abatir o matar. Poco tiempo había pasado cuando los perros dieron con el rastro de aquella fiera y fueron pronto en su seguimiento, a cuyos ladridos concurrían los cazadores, y fueron siguiendo a los perros hasta una abertura que se veía entre unos roqueríos. Apenas habían llegado a la gruta, cuando salió de dentro, como un rayo, una fiera tan horrible y espantosa, que atemorizó a todos los que de lo alto del monte la veían. Embistió a los perros y, sin demora o resistencia, los fue despedazando de cuatro en cuatro, pues al mismo tiempo lanzaba cuatro garras con tal violencia que con un mismo golpe dejaba por tierra a cuatro perros, por más valientes que fueran. Los dos primeros cazadores que llegaron, apenas avistaron a la fiera, dispararon sus escopetas que tenían preparadas y bien cargadas de balas, pero fue una diligencia frustrada porque las balas chocaron en aquel cuerpo, como si fuera un grueso fierro o en una fuerte muralla. Luego, la fiera corrió atrevidamente 
contra los que le habían tirado, y aunque estos intentaban escapar, no les fue posible, porque era tanta la velocidad con la que aquella bestia corría que a los pocos pasos los alcanzó y de un golpe les abrió tan grande herida que les aparecieron las entrañas. Apenas despedazó a estos, corrió detrás de otros, los que no esperaron en huir, mas aquella bestia embravecida corría con tal ligereza que en poco espacio los capturó y, con la misma fiereza, los abrió por el medio.

Clamaba el Corregidor persuadido de que si todos disparaban alguno le acertaría en su parte vital. Pero estaban todos tan apremiados y con tal terror que parecían más estatuas desanimadas que cuerpos animados. Unos que estaban en un sitio al parecer más seguro, por estar puestos en la cuesta de la montaña, se animaron a disparar sus escopetas todos al mismo tiempo, pero con consecuencia funesta, como ocurrió con los primeros, porque se veían saltar las balas por fuera, quebrantando sus fuerzas pero no el cuerpo de aquel Monstruo, sin que ninguna penetrase. No se demoró mucho en buscar a sus agresores, corriendo por la montańa con tanta destreza, que más parecía volar que escalar por aquellos altísimos peñascos, pues tenía unas especies de alas y con ellas se ayudaba tanto en la carrera que, (Folio 12) a pesar de que todos huyeran con la mayor prisa que podían, en brevísimo tiempo alcanzó a los que lo habían atacado y con la misma fuerza los tiró por tierra. Todos huían para diversas partes y en esto únicamente consistió su fortuna, porque en cuanto aquella fiera seguía a unos, permitía que otros pudieran escapar. Finalmente, acabó esta infausta cacería con la muerte de veintisiete hombres que fueron lamentablemente el despojo de aquel horroroso Monstruo. Retiráronse los otros [los que quedaban vivos] con carrera precipitada y después a paso siempre acelerado. Llegaron finalmente al pueblo, donde contaron a los parientes y amigos el trágico suceso de la empresa, reconociendo todos que debían su vida a la ligereza de sus pies, pues si no se hubieran retirado con tanta prisa, todos habrían sido víctimas de aquella furia. En todas las casas y en todos los ayuntamientos no se hablaba de otra cosa, discurriendo cada uno conforme a su impresión.

$\mathrm{Al}$ día siguiente se juntaron los principales del pueblo para resolver qué se debía hacer, porque decían, por supuesto, como todos reconocían, que era imposible atrapar por la fuerza a aquella indómita bestia. Era preciso usar algún medio ingenioso o artificio para matarla. Porque faltándole sustento, descendería al pueblo donde causaría mayores estragos, y porque si en verdad fuera de aquella especie de Dragones en cuya cabeza se hallaba la piedra preciosa de Carbúnculo, no era bueno que se les escapase de las manos tan grande tesoro. Pareció una determinación acertada, como concordaron todos, que debía abrirse una cueva muy profunda en las entradas de aquel valle, por donde la dicha fiera hubiese de pasar, cubierta como si fuera una cima, que caminando sin advertir cayese a la cueva, la cual siendo profunda y lisa, de suerte que no tuviese por donde afirmar sus pies, no podría subir a la cima, incluso si se ayudase de sus alas. Pues como habían advertido los que se hallaron presentes en la cacería, las alas de aquella bestia no servían para volar, sino que solamente se ayudaba de ellas para subir con más prisa por el camino inclinado y lleno de farellones. Y para que no sucediese que cuando los hombres se ocuparan de cavar y abrir la cueva acudiese al estruendo aquella bestia y los despedazase, mandaron hacer un enrejado de fierro alto con grandes puntas agudas en su extremo y por los lados, debajo del cual los 
trabajadores cavasen con seguridad. Así se ejecutó. Y para llegar con toda tranquilidad al lugar, aseguraron una entrada estrecha (Folio 13) que quedaba entre dos montes altos, y allí puesto el enrejado de fierro quedaron solamente debajo de él los que debían trabajar y los demás se retiraron. Comenzaron a abrir la cueva y prosiguieron su trabajo hasta hacerla muy profunda y lisa con éxito, pues como esta entrada estaba bastante lejana de la gruta donde habitaba el monstruo, no fueron sentidos por él. Se gastaron algunos días en la obra y después de estar todo preparado, enrejaron la parte por fuera de la cueva, quedándose dos bajo ella con unas bocinas, y los demás se retiraron a cierta distancia, para que al oírse la señal que habían acordado, acudiesen al mismo sitio.

Estando todo dispuesto, los que estaban debajo del enrejado de fierro comenzaron a gritar con fuerza y a tocar las bocinas, y sus voces entraron por aquel estrecho extendiéndose por aquel dilatado valle, llegando finalmente a los oídos del Monstruo. Acudió pronto y corriendo con toda la prisa al lugar de donde sentía el estruendo, se metió por la entrada de los dos montes y apenas avistó a los hombres que tocaban las cornetas, emprendió una carrera como un rayo, sin reparar donde ponía los pies hasta llegar al lugar en donde estaba abierta la cueva bien cubierta. Y apenas llegó allí cayó precipitadamente al fondo. Dieron pronto seńal y acudieron la mayoría a toda prisa. Y viendo al monstruo dentro de la cueva, saltaban de contentos. Luego trataron de asegurarla más, poniéndole la misma reja de fierro encima, tornada con las puntas para abajo, por si el animal forcejeaba con sus garras y pretendiese salir, las grandes y muchas puntas de fierro que tenía y su peso se lo impidiesen. Eran tan grandes los gritos y rugidos que daba aquella fiera embravecida que atemorizaba, pero como los participantes ya se daban por seguros, comenzaron con más sosiego a observar las características que de ella notaban, las cuales conforme refirieron son las siguientes:

En primer lugar, tenía aquel Monstruo dos cabezas, una que parecía de águila y otra que tenía semejanzas de león. Le salía de esta cabeza una punta aguda como de Unicornio. Tenía seis orejas y el cuello una gran melena. Se le veían cuatro manos y cuatro pies. Dos pies y dos manos parecían de águila. Los otros representaban las garras de un gran león. En todas ellas había uñas tan delgadas en los bordes como gruesas junto a sus dedos, de color trigueño, y lucían y mostraban tener (Folio 14) una longitud de medio palmo. Tenía una cola muy larga que levantaba alto, cuya extremidad era más gruesa y con muchos pelos, entre lo cual abría de vez en vez una película por ambas bandas a la manera de párpados de ojos, y al mismo tiempo que se abría, lanzaba desde dentro una luz muy clara y resplandeciente, aunque esta no se percibía tanto de día como en la noche. El cuerpo estaba todo cubierto de conchas de reflejos cambiantes, pues conforme era el reflejo de la luz del sol, así era también la variedad de colores que representaba, sin embargo, eran tan duras que por más que le dispararon muchos tiros desde la boca de la cueva, así como balas como cuartos, golpeaban las balas las dichas conchas y rebotaban hacia fuera, no provocando los tiros una mayor impresión en la fiera, como si se golpeasen en un duro acero. Mostraba tener de longitud quince o dieciséis palmos y de alto ocho o nueve. Se observó que junto a su vientre tenía dos pieles, una en cada lado a modo de dos bolsillos, en los cuales traía los hijos pequeños. Tenía dos alas como de serpiente, no de plumas, sino compuestas, conforme a lo que representaban, de unos nervios gruesos, 
duros y con escamas. Los hijos que había traído al lugar referido, como eran aún pequeños fueron penetrados por las balas y cayeron dos muertos. E hicieron reflexión de que la fiera se embraveció más cuando vio correr la sangre y la muerte de sus dos hijos. Como, no obstante, no se podía matar por más diligencias que hicieron, se resolvió volver al pueblo y dar cuenta de lo sucedido. Quedaron de observar entre tanto lo que pasaba. No cesaba aquella feroz fiera de gritar y así estuvo hasta el día siguiente, en que concurrió mucha gente a ver aquel nuevo y celebrado prodigio, trayendo una gran cantidad de cadenas de fierro para sujetarla.

Venían todos muy contentos, pero apenas llegaron a una distancia en donde se podía oír, algunos repararon en que habían gritos diferentes, y un indio que allí era más precavido, decía a los demás que tenía la desconfianza de que estuviese llamando a otros con los rugidos que daba estando preso. Se asustaron todos y juzgaron que para mayor precaución subiese uno a una de las alturas de la montańa que quedaba a un lado, desde la cual, por ser muy elevada, se podría observar el sitio en donde estaba armada la trampa. Así sucedió, mas apenas había subido a lo alto, descendió a toda prisa, afirmando que estaban dos al pie de la (Folio 15) cueva cavando la tierra con gran ímpetu, y que ya tenía desprendida una parte del enrejado de fierro que estaba sobre la misma cueva. Escuchando esto, ni uno se detuvo, siguieron todos para sus casas. Sin embargo, algunos de mayor ánimo, y amigos de los que habían quedado de guardia a los pies de la cueva, volvieron a la misma montańa para de allí observar si los veían. Llevaron la noticia de que los vieron despedazados junto al lugar donde estaban los dos monstruos, que continuaban cavando la tierra, como con la intención de abrirla de modo que pudiese salir el que estaba dentro. Se mandaban repetidas veces ir a observar si aquellas fieras se habían ido de aquel sitio, mas siempre continuaban con la misma diligencia, y los que para allá iban decían que siempre veían a ambas o al menos una. Andaban todos con gran miedo, por el susto de que estos monstruos descendieran al pueblo, que no se oía hablar de otra cosa. Se hicieron muchas reuniones, juntándose la gente principal y la más criteriosa para encontrar algún medio con que se pudiese atacar un gran peligro como ese. Pero hasta el presente no se tiene tomada resolución alguna, porque todos los medios y arbitrios que se tienen propuestos son muy dificultosos e impracticables, puesto que abrir nuevas cuevas para que cayeran los otros [monstruos] no es posible, porque pasado aquel estrecho en que estaban las referidas fieras no hay por allí otro lugar estrecho por donde ellas podrían pasar, ya que este sitio se va dilantando en valles muy largos y espaciosos. De manera que no hay lugares adecuados para armar otras trampas, por lo que se encuentran todos con gran consternación y muchos se han retirado para Guasco. Se mandó aviso a la ciudad de Santiago y al Gobernador de este Reino que reside en la ciudad de Concepción de todo lo que había pasado. Estamos esperando la respuesta, para al fin ver en qué va a parar este caso tan espantoso.

FIN.

LISBOA, Oficina de MIGUEL MANESCAL DA COSTA, Impresor del Santo Oficio. Año de 1751.

Con las licencias necesarias. (Folio 16) 


\section{OBRAS CITADAS}

Barrera Osorio. Antonio. 2009. "Experiencia y empirismo en el siglo XVI: reportes y cosas del Nuevo Mundo”. Memoria y Sociedad 13:13-25.

Bénat-Tachot, Louise; Gruzinski, Serge y Jeanne, Boris. 2012. Les processus d'americanisation. Ouvertures théoriques. Tomo I. Paris: Éditions le Manuscrit,

Bethencourt, Francisco. 1997. La Inquisición en la época moderna. España, Portugal, Italia, siglos XV-XIX. Madrid: Ediciones Akal.

Birmingham, David. 1995. Historia de Portugal. New York: Cambridge University Press.

Céard, Jean. 1977. La nature et les prodiges. L'insolite au XVIe siècle. Genève: Droz.

Cohen, Jeffrey Jerome. 1996. "Monster Culture (Seven Thesis)". En Monster Theory: Reading Culture, Ed. J. J. Cohen. Minneapolis: University of Minnesota. 3-25.

Doré, Andrea. 2014. "O deslocamento de interesses da Índia para o Brasil durante a União Ibérica: mapas e relatos”. Colonial Latin American Review 23:171-196.

Ebben, Mauricio. 1993. "Un triángulo imposible la Corona española, el Santo Oficio y los banqueros portugueses, 1627-1655”. Hispania: Revista española de historia 53:541556.

Fortanet, Joaquin. 2015. "Anatomía de la monstruosidad: la figura del monstruo como objeto de la mirada médico-anatómica moderna". Asclepio. Revista de Historia de la Medicina y de la Ciencia 67:1-11.

Godoy Gallardo, Eduardo. 2009. "Chiloé: tierra de brujerías, prodigios y encantamientos. Monstruos y Prodigios en la literatura hispánica, Ed. M. Insúa y L. Peres, Madrid, Frankfurt: Iberoamericana, Vervuert. 117-134.

Hernández-Ramírez, Azucena. 2016. "Barroco, monstruosidad y mercancía en Historia General y Natural de las Indias, de Gonzalo Fernández Oviedo”. Hispanic Review 84:69-92.

Iglesias Castellano, Abel. 2013. "Partos extraordinarios: la representación de lo monstruoso en la España Moderna a través de las relaciones de sucesos”. eHumanista 24:433465.

Insúa Cereceda, Mariela. 2009. "De asombros, horrores y fatalidades: algunos apuntes acerca de las relaciones de monstruos (siglos XVII y XVIII)". Monstruos y Prodigios en la literatura hispánica, Ed. M. Insúa y L. Peres. Madrid, Frankfurt Iberoamericana, Vervuert.

Izzi, Massimo. 2000. Diccionario Ilustrado de los Monstruos. Ángeles, diablos, ogros, dragones, sirenas y otras criaturas del imaginario. Mallorca, Barcelona, Alejandría: José de Olañeta.

Morgan, Luke. 2016. The Monster in the Garden. The grotesque and the gigantic in Renaissance Landscape Desing. Philadelphia: Penn.

Oliva Santiesteban, Héctor. 2003. Tratado de monstruos: Ontología teratológica. MéxicoPlaza y Valdés, México.

Onetto, Mauricio. 2017. Temblores de Tierra en el Jardín del Edén. Desastre, memoria e 
identidad en Chile, siglos XVI-XVIII. Santiago de Chile: DIBAM.

Pastor, Beatriz. 1993. "Utopía y conquista: Dinámica utópica e identidad colonial". Revista de Crítica Literaria Latinoamericana 19:105-113.

Prieto, Andrés. 2010. "Maravillas, monstruos y portentos: la naturaleza chilena en la Histórica Relación del Reyno de Chile (1646), de Alonso de Ovalle". Taller de Letras 47:9-27.

Reyes Gil, Sebastián. 2015. "Animalidad y sexualidad en tres casos monstruosos de la crónica peruana (siglos XVI y XVII)”. Hispanic Review 83:423-443.

Río Parra, Elena. 2003. Una era de Monstruos. Representaciones de lo deforme en el Siglo de Oro español. Madrid, Pamplona: Universidad de Navarra Iberoamericana.

Rodini, Elizabeth. 2000. Baroques Pearls. Art Institute of Chicago Museum Studies 25.2 Renaissance Jewelry in the Alsdorf Collection: 68-69.

Rojas Mix, Miguel. 2015. América Imaginaria. Santiago: Erdosain Ediciones.

Romero Magalhaes, Joaquim. 1992. "La Inquisición portuguesa: intento de periodización". Revista de la Inquisición 2: 71-93.

Said, Edward. 2005. L'Orientalisme. L'Orient créé par l'Occident. Paris : Éditions du Seuils.

Scafi, Alessandro. 2013. Maps of Paradise. Chicago, London: The University of Chicago Press.

Torrano, Andrea. 2015. "La monstruosidad en G. Canguilhem y M. Foucault. Una aproximación al monstruo biopolítico". Agora: Papeles de filosofía 34:87-109.

Vega Ramos, María José. 1995. "La monstruosidad y el signo formas de la presignificación en el Renacimiento y la Reforma". Signa: Revista de la Asociación Española de Semiótica 4:225-242.

Vega, Alejandra. 2014. Los Andes y el territorio de Chile en el siglo XVI. Descripción, reconocimiento e invención. Santiago: DIBAM.

Vidal, Hernán. 2005. "Aesthetic Categories as Empire Administration Imperatives: The Case of the Baroque". Hispanic Baroques: Reading Cultures in Context. Ed. N. Spadaccini y L. Estudillo. Nashville: Vanderbilt University Press. 20-51. 
